\title{
Importance of the plasma soluble HLA-G levels for prognostic stratification with traditional prognosticators in colorectal cancer
}

\author{
Jing-Bo Li ${ }^{1}$, Yan-Yun Ruan' ${ }^{2}$, Bin Hu${ }^{1}$, Shan-Shan Dong ${ }^{2}$, Tie-Nan $\mathrm{Bi}^{3}$, Aifen Lin ${ }^{2}$ and \\ Wei-Hua Yan ${ }^{1,4}$ \\ ${ }^{1}$ Medical Research Center, Taizhou Hospital of Zhejiang Province, Wenzhou Medical University, Linhai, Zhejiang, People's \\ Republic of China \\ ${ }^{2}$ Human Tissue Bank, Taizhou Hospital of Zhejiang Province, Wenzhou Medical University, Linhai, Zhejiang, People's Republic \\ of China \\ ${ }^{3}$ Department of Gastrointestinal Surgery, Taizhou Hospital of Zhejiang Province, Wenzhou Medical University, Linhai, \\ Zhejiang, People's Republic of China \\ ${ }^{4}$ Department of Laboratory Medicine, Xianju People's Hospital, Xianju, Zhejiang, People's Republic of China \\ Correspondence to: Wei-Hua Yan, email: yanwhcom@yahoo.com \\ Aifen Lin, email: aifenlin@yahoo.com
}

Keywords: soluble HLA-G, colorectal cancer, prognosis

Received: November 07, $2016 \quad$ Accepted: March 13, $2017 \quad$ Published: March 22, 2017

Copyright: Li et al. This is an open-access article distributed under the terms of the Creative Commons Attribution License 3.0 (CC BY 3.0), which permits unrestricted use, distribution, and reproduction in any medium, provided the original author and source are credited.

\section{ABSTRACT}

An increased peripheral soluble HLA-G (sHLA-G) expression has been observed in various malignancies while its prognostic significance was rather limited. In this study, the prognostic value of plasma sHLA-G in 178 colorectal cancer (CRC) patients was investigated. sHLA-G levels were analyzed by specific enzyme-linked immunosorbent assay. Data showed SHLA-G levels were significantly increased in CRC patients compared with normal controls $(36.8 \mathrm{U} / \mathrm{ml}$ vs $25.4 \mathrm{U} / \mathrm{ml}, p=0.009)$. sHLA-G in the died were obviously higher than that of alive CRC patients $(46.8 \mathrm{U} / \mathrm{ml}$ vs $27.4 \mathrm{U} / \mathrm{ml}, p=0.012$ ). Patients with sHLA-G above median levels $(\geq 36.8 \mathrm{U} / \mathrm{ml}$, sHLA-G ${ }_{\text {high }}$ ) had a significantly shorter survival time than those with SHLA-G low $_{\text {, }}$ $(<36.8 \mathrm{U} / \mathrm{ml}, p<0.001)$, and sHLA-G could be an independent prognostic factor for CRC patients. With stratification of clinical parameters in survival by SHLA-G low $_{\text {and }}$ and sHLA-G high sHLA-G exhibited a significant predictive value for CRC patients of the female $(p=0.036)$, the elder $(p=0.009)$, advanced tumor burden $\left(T_{3+4^{\prime}}, p=0.038\right)$, regional lymph node status $\left(N_{0}, p=0.041\right)$, both metastasis status $\left(M_{0}, p=0.014\right)$ and $(M 1, p=0.018)$, and clinical stage $(I+I I, p=0.018)$, respectively. Summary, our data demonstrated for the first time that SHLA-G levels is an independent prognosis factor and improves the prognostic stratification offered by traditional prognosticators in CRC patients.

\section{INTRODUCTION}

In China, CRC incidence and mortality have been increasing during the last decade, resulting in an estimated 376,300 new cases and 191,000 deaths in 2015 [1]. The immune system has proven to play critical roles in tumorigenesis. Various strategies such as induction of regulatory cells, alteration of antigen presentation and production of immune suppressive mediators, have been developed by tumor cells to have a successful immune evasion [2]. For the importance of the host immune system involved in tumor progression, previous literatures have demonstrated the impact of immune-classification (termed Immunoscore), and its prognostic value has been demonstrated superior to the classical TNM classification for $\mathrm{CRC}$ [3-5].

HLA-G, a potent immune suppressive mediator firstly observed in cytotrophoblasts, has been observed in various malignancies and strongly associated with tumor immune escape, metastasis and patient survival [6]. HLA-G can be expressed as seven different isoforms, including four membrane bound (HLA-G1 to -G4) and 
three soluble (HLA-G5 to -G7) molecules. Previous studies revealed that both membrane-bound and SHLA-G isoforms could render multiple immune suppressive effects during the progression of malignancies, with involved mechanisms by inhibiting immune cell function, inducing apoptosis and the generation of regulatory cells through receptor binding and/or trogocytosis, and impairing chemotaxis of different immune effector cells [7, 8].

HLA-G expression was observed in sources such as on the tumor cell, secreted, or in tumor-derived exosomes $[9,10]$. A high frequency of tumor cell HLA-G expression and/or increased sHLA-G levels has been found in various body fluids in a variety of cancers [11]. An increased lesion HLA-G expression or peripheral sHLA-G levels were associated with clinical parameters such as advanced disease stage, tumor metastasis and/or worse prognosis in tumor patients [12-14]. In addition to the tumor lesion HLA-G expression was intensively investigated; however, the value of peripheral sHLA-G in prognosis is very limited but now emerging $[8,9]$.

In this context, previous studies revealed that sHLA-G could be a good diagnostic factor to distinguish benign colorectal related disease from CRC [15]. In gastric cancer (GC), our study indicated that plasma sHLA-G level was a potential biomarker for GC diagnosis [16]. Moreover, circulation sHLA-G levels is an independent risk factor for patients with non small cell lung cancer (NSCLC) was reported in previous studies [17-19].

In this study, plasma sHLA-G levels in $178 \mathrm{CRC}$ patients were tested, and its correlation to clinical parameters and prognosis of the CRC patients was investigated.

\section{RESULTS}

\section{Plasma sHLA-G levels in CRC patients}

In CRC patients, sHLA-G (median: $36.8 \mathrm{U} / \mathrm{ml}$; range: $1.6-531.0)$ were significantly increased compared with normal controls (median: $25.4 \mathrm{U} / \mathrm{ml}$; range: 3.6-97.1; $p=0.009$ ). Furthermore, significantly higher sHLA-G were observed in the dead (46.8 U/ml, range: $3.3-531.0)$ than that in the alive CRC patients $(27.4 \mathrm{U} / \mathrm{ml}$, range: 1.6-511.4; $p=0.012$; Figure 1). However, sHLA-G were not associated with the tumor type, patient gender, age, TNM status and disease stage (Table 1).

\section{Plasma sHLA-G related to survival in CRC patients}

To investigate the relationship between plasma sHLA-G and the survival of the CRC patients, sHLA-G was stratified to two groups as below ( $\mathrm{sHLA}-\mathrm{G}_{\text {low }}$ ) or above $\left(\mathrm{sHLA}-\mathrm{G}_{\text {high }}\right)$ the median of $36.8 \mathrm{U} / \mathrm{ml}$. The significance of other factors for the prognosis such as patient gender, age, extent of primary tumor $(\mathrm{T})$, regional lymphnode status $(\mathrm{N})$, distant metastases $(\mathrm{M})$, and disease stage was also analyzed.

CRC patients with sHLA-G $\mathrm{G}_{\text {high }}(n=89)$ had a significantly worse prognosis than patients with sHLA$\mathrm{G}_{\text {low }}(n=89 ; p=0.004)$. The median survival time for the sHLA-G ${ }_{\text {low }}$ patients was 62.9 months (95\% CI: 56.3-69.5), and for the sHLA-G $\mathrm{G}_{\text {high }}$ patients was 49.2 months (95\% CI: 42.2-56.1; Figure 2A).

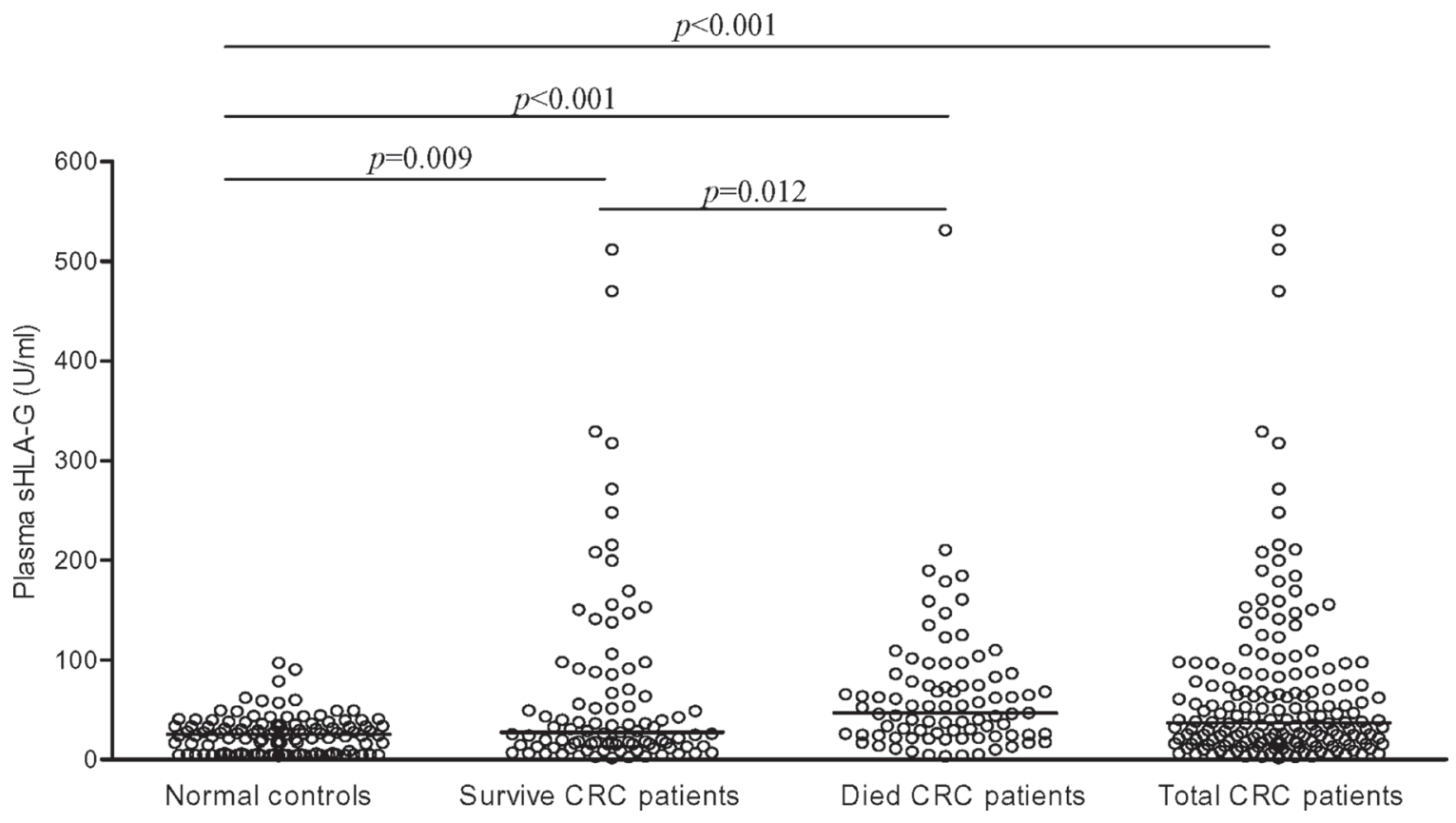

Figure 1: sHLA-G levels in healthy controls and CRC patients. Bars represent the median values. 
Table 1: Association of sHLA-G expression with clinicopathological parameters in colorectal cancer patients

\begin{tabular}{|c|c|c|c|}
\hline Variables & No. of cases & sHLA-G median (range, U/ml) & $p^{*}$ \\
\hline Colorectal cancer patients & 178 & $36.8(1.6-531.0)$ & \\
\hline \multicolumn{4}{|l|}{ Tumor type } \\
\hline colon cancer & 59 & $45.8(3.3-531.0)$ & \multirow{2}{*}{0.125} \\
\hline rectal cancer & 119 & $35.7(1.6-215.4)$ & \\
\hline \multicolumn{4}{|l|}{ Survival status } \\
\hline dead & 85 & $46.8(3.3-531.0)$ & \multirow{2}{*}{0.012} \\
\hline alive & 93 & $27.4(1.6-511.4)$ & \\
\hline \multicolumn{4}{|l|}{ Gender } \\
\hline male & 100 & $33.0(2.8-317.5)$ & \multirow[b]{2}{*}{0.122} \\
\hline female & 78 & $43.3(1.6-531.0)$ & \\
\hline \multicolumn{4}{|l|}{ Age } \\
\hline$\leq$ median $(65$ years $)$ & 95 & $33.7(2.8-511.4)$ & \multirow{2}{*}{$0.10 \varsigma$} \\
\hline$>$ median & 83 & $45.8(1.6-531.0)$ & \\
\hline \multicolumn{4}{|l|}{$\mathrm{T}$ category } \\
\hline $\mathrm{T}_{1+2}$ & 27 & $32.5(1.6-511.4)$ & \multirow[b]{2}{*}{0.243} \\
\hline $\mathrm{T}_{3+4}$ & 142 & $37.6(3.2-531.0)$ & \\
\hline \multicolumn{4}{|l|}{$\mathrm{N}$ category } \\
\hline $\mathrm{N}_{0}$ & 79 & $34.3(1.6-511.4)$ & \multirow{2}{*}{0.263} \\
\hline $\mathrm{N}_{1+2}$ & 90 & $40.1(3.2-531.0)$ & \\
\hline \multicolumn{4}{|l|}{ M category } \\
\hline $\mathrm{M}_{0}$ & 163 & $36.6(1.6-531.0)$ & \multirow{2}{*}{0.324} \\
\hline $\mathrm{M}_{1}$ & 6 & $17.8(5.2-134.9)$ & \\
\hline \multicolumn{4}{|l|}{ Disease stage } \\
\hline I & 24 & $33.4(1.6-511.4)$ & \multirow{4}{*}{0.582} \\
\hline II & 54 & $36.2(3.3-469.9)$ & \\
\hline III & 85 & $40.1(3.2-531.0)$ & \\
\hline IV & 6 & $17.8(5.2-134.9)$ & \\
\hline
\end{tabular}

*Comparison of sHLA-G expression status between or among each variable using the Mann-Whitney $U$ test.

Other factors including patient age, $\mathrm{T}$ and $\mathrm{N}$ status, and disease stage was found significantly associated with survival. Patients with the age below $(n=95)$ had a notably longer survival than those with the age above the median of 65 years $[n=83$; median: 62.4 months $(95 \%$ CI: $56.0-68.8)$ vs 48.8 months (95\% CI: $41.61-156.1$ ), $p=0.005 ;$ Figure 2B]. Primary tumor status $\mathrm{T}_{1+2}(n=27)$ had a notably longer survival than those with $\mathrm{T}_{3+4}[n=142$; median: 80.0 months (95\% CI: 72.2-87.8) vs 53.0 months (95\% CI: 47.6-58.5); $p<0.001$; Figure 2C]. Patients with $\mathrm{N}_{0}(n=79)$ had a longer survival than those with $\mathrm{N}_{1+2}$ [ $n=90$; median: 72.4 months (95\% CI: 66.5-78.3) vs 44.0 months (95\% CI: 37.4-50.7; $p<0.001$; Figure 2D]. Moreover, Patients with advanced disease stage had a remarkably shorter survival time $(p<0.001)$, with the survival time for stage I [ $n=24$; median: 81.8 months; (95\% CI: 74.5-89.1)], II [ $n=54$; median: 68.0 months; (95\% CI: 60.4-75.7)], III [ $n=85$; median: 44.8 months; (95\% CI: $38.0-51.6)$ ], and stage IV [ $n=6$; median: 24.0 months; (95\% CI: 6.5-41.5)], respectively (Figure 2E). However, no statistical difference was observed between the male $(n=100)$ and female patients $(n=78)$ (median: 55.3 months vs 56.9 months; $p=0.777$; Figure 2F), and similar data was found for tumor metastasis status, though the survival is much longer in patients with $\mathrm{M}_{0}(n=163)$ than those with $\mathrm{M}_{1}(n=6$; median: 58.2 months $v s 36.6$ months; $p=0.160$; Figure 2G).

To evaluate whether sHLA-G is a prognostic factor for CRC patients, Cox's proportional hazards model analysis was performed. In addition to sHLA-G, 
clinicopathological parameters including patient age, gender, TNM status and disease stage was included. Univariate analysis showed that variates such as SHLA-G $(p=0.005, \mathrm{HR}=1.870)$, patient age $(p=0.006$, $\mathrm{HR}=1.830), \mathrm{T}$ status $(p<0.001, \mathrm{HR}=3.525), \mathrm{N}$ status $(p<0.001, \mathrm{HR}=4.021)$ and disease stage $(p<0.001$, $\mathrm{HR}=3.887$ ), all were significantly to a poor prognosis. Moreover, multivariate analysis revealed that, besides the patient age and primary tumor status, sHLA-G was an independent prognostic factor ( $p=0.047, \mathrm{HR}=1.622$ ). These results indicated that the sHLA-G was an independent prognostic factor for CRC patients (Table 2).

For multiple comparisons are done including T, N, and disease stage, Bonferroni correction was performed. Because only 3 patients were $T_{1}$ and 5 patients were $T_{4}$,
Bonferroni correction was not performed. Among the $\mathrm{N}$ status, data showed that survival for patients with $\mathrm{N}_{1}$ and $\mathrm{N}_{2}$ was worse than patients with $\mathrm{N}_{0}\left(\right.$ all $\left.p_{\mathrm{c}}<0.001\right)$, while no significance was observed between the $\mathrm{N}_{1}$ and $\mathrm{N}_{2}$ $\left(p_{\mathrm{c}}=0.717\right)$. Survival for the disease stages, patients with III and IV were worse than those with I $\left(p_{\mathrm{c}}=0.004\right.$ and $\left.p_{\mathrm{c}}<0.001\right)$ and II $\left(p_{\mathrm{c}}<0.001\right.$ and $\left.p_{\mathrm{c}}=0.088\right)$, respectively. However, survival between patient with I and II $\left(p_{\mathrm{c}}=0.168\right)$, III and IV ( $p=0.746)$ were not significant (Table 3$)$.

\section{sHLA-G levels on the prognostic stratification of clinical parameters in CRC patients}

Then, we analyzed the prognostic significance of sHLA-G with stratification of clinical parameters in CRC
A

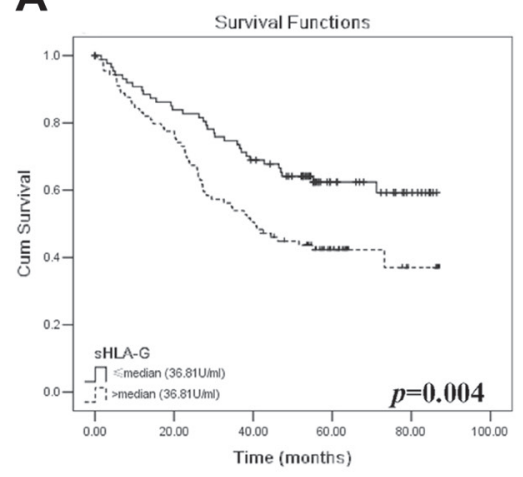

D

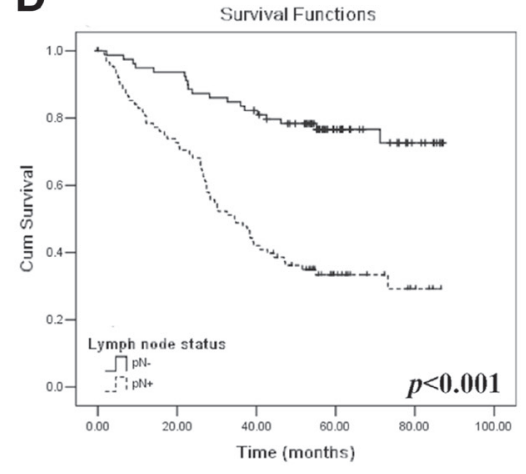

B

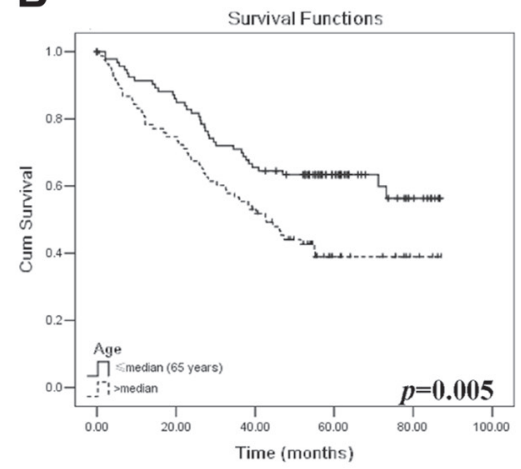

E

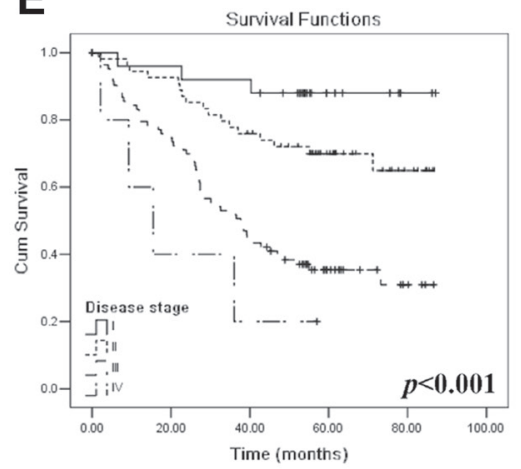

G

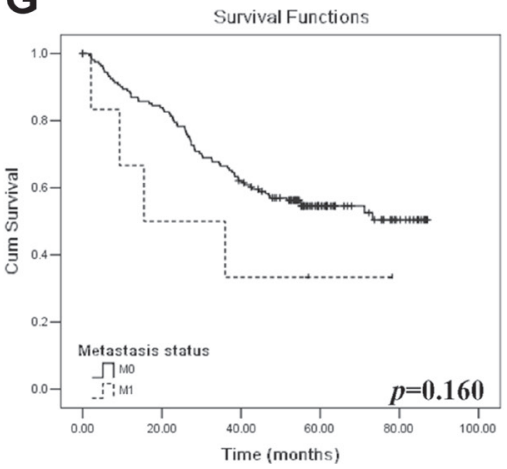

C

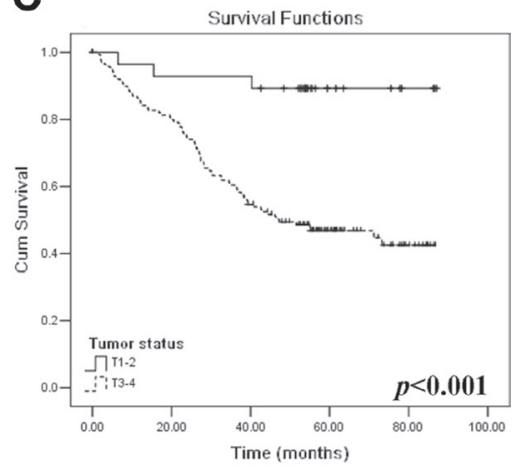

$\mathbf{F}$

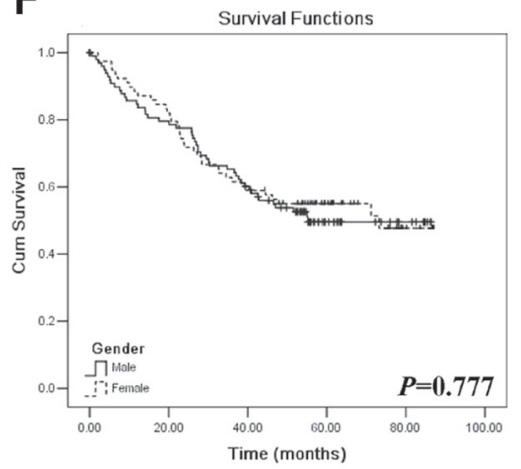

Figure 2: Kaplan-Meier survival analysis for CRC patients. Comparison of the overall survival between the (A) patients with sHLA-G $\mathrm{G}_{\text {high }}(n=89)$ and sHLA-G $\mathrm{G}_{\text {low }}(n=89)$; (B) patients with age above $(n=83)$ and below $(n=95)$ the median of 65 years; $(\mathbf{C}) \mathrm{T}_{1+2}$ $(n=27)$ and $\mathrm{T}_{3+4}(n=142)$; (D) $\mathrm{N}_{0}(n=79)$ and $\mathrm{N}_{1+2}(n=90) ;(\mathbf{E})$ disease stages I $(n=25)$, II $(n=54)$, III $(n=85)$ and IV $(n=6)$; (F) male $(n=100)$ and female $(n=78)$ patients, and $(\mathbf{G}) \mathrm{M}_{0}(n=163)$ and $\mathrm{M}_{1}(n=6)$ of CRC patients. 
Table 2: Cox proportional hazards model analysis of variables affecting survival in colorectal cancer patients

\begin{tabular}{|c|c|c|c|c|c|}
\hline \multirow{3}{*}{ Variables } & \multirow{3}{*}{ Categories } & \multirow{2}{*}{\multicolumn{2}{|c|}{$\begin{array}{c}\text { Univariate Analysis } \\
\text { Overall survival }\end{array}$}} & \multirow{2}{*}{\multicolumn{2}{|c|}{$\begin{array}{c}\text { Multivariate Analysis } \\
\text { Overall survival }\end{array}$}} \\
\hline & & & & & \\
\hline & & HR $(95 \%$ CI) & $P$-value & HR (95\% CI) & $P$-value \\
\hline Gender & Male ( $v s$ female) & $0.940(0.612-1.443)$ & 0.776 & & \\
\hline Age (years) & $>65(v s \leq 65)$ & $1.830(1.189-2.816)$ & 0.006 & $1.909(1.202-3.033)$ & 0.006 \\
\hline T category & $\mathrm{T}_{3+4}\left(v s \mathrm{~T}_{1+2}\right)$ & $3.525(1.898-6.547)$ & $<0.001$ & $2.044(1.062-3.934)$ & 0.032 \\
\hline $\mathrm{N}$ category & $\mathrm{N}_{1+2}\left(v s \mathrm{~N}_{0}\right)$ & $4.021(2.391-6.764)$ & $<0.001$ & $1.759(0.409-7.573)$ & 0.448 \\
\hline M category & $\mathrm{M}_{1}\left(v s \mathrm{M}_{0}\right)$ & $2.029(0.741-5.554)$ & 0.168 & $1.701(0.541-5.349)$ & 0.363 \\
\hline Disease stage & $\mathrm{III} / \mathrm{IV}(v s \mathrm{I} / \mathrm{II})$ & $3.887(2.311-6.538)$ & $<0.001$ & $1.833(0.436-7.709)$ & 0.408 \\
\hline sHLA-G (U/ml) & $>36.8(v s \leq 36.8)$ & $1.870(1.207-2.897)$ & 0.005 & $1.622(1.006-2.615)$ & 0.047 \\
\hline
\end{tabular}

Abbreviations: HR $=$ hazard ratio; 95\% CI $=95 \%$ confidence interval; TNM, lymph-node-metastasis and disease stage according to the TNM classification for colorectal cancer (UICC).

Table 3: Log-rank Mantel-Cox analysis of multi-variables affecting survival in colorectal cancer patients

\begin{tabular}{|c|c|c|c|c|c|c|}
\hline Variables & $\begin{array}{l}\text { No. } \\
\text { Total }\end{array}$ & $\begin{array}{c}\text { No. } \\
\text { Events }\end{array}$ & $\begin{array}{c}\text { Survival time } \\
\text { Mean }(95 \% \text { CI })\end{array}$ & $P$-value ${ }^{*}$ & HR $(95 \%$ CI) & $P$-value* \\
\hline \multicolumn{7}{|l|}{ N category } \\
\hline Whole cohort & 169 & 78 & $57.5(52.6-62.5)$ & $p_{\mathrm{c}}<0.001$ & $2.110(1.615-2.755)$ & $p_{\mathrm{c}}<0.001$ \\
\hline $\mathrm{N}_{0}$ & 79 & 19 & $72.4(66.5-78.3)$ & & & \\
\hline $\mathrm{N}_{1}$ & 49 & 30 & $46.4(37.8-55.0)$ & & & \\
\hline $\mathrm{N}_{2}$ & 41 & 29 & $39.7(30.0-49.4)$ & & & \\
\hline $\mathrm{N}_{1}$ vs. $\mathrm{N}_{0}$ & & & & $p_{\mathrm{c}}<0.001$ & $3.546(1.989-6.321)$ & $p_{\mathrm{c}}<0.001$ \\
\hline $\mathrm{N}_{2} v s . \mathrm{N}_{0}$ & & & & $p_{\mathrm{c}}<0.001$ & $2.164(1.615-2.899)$ & $p_{\mathrm{c}}<0.001$ \\
\hline $\mathrm{N}_{2}$ vs. $\mathrm{N}_{1}$ & & & & $p_{\mathrm{c}}=0.717$ & $1.358(0.814-2.265)$ & $p_{\mathrm{c}}=0.723$ \\
\hline \multicolumn{7}{|l|}{ Disease stage } \\
\hline Whole cohort & 169 & 78 & $57.5(52.6-62.5)$ & $p_{\mathrm{c}}<0.001$ & $2.490(1.789-3.467)$ & $p_{\mathrm{c}}<0.001$ \\
\hline I & 24 & 2 & $81.8(74.5-89.1)$ & & & \\
\hline II & 54 & 17 & $68.0(60.4-75.7)$ & & & \\
\hline III & 85 & 55 & $44.8(38.0-51.6)$ & & & \\
\hline IV & 6 & 4 & $24.0(6.50-41.5)$ & & & \\
\hline II $v s . \mathrm{I}$ & & & & $p_{\mathrm{c}}=0.168$ & $4.068(0.939-17.63)$ & $p_{\mathrm{c}}=0.244$ \\
\hline III vs. I & & & & $p_{\mathrm{c}}=0.004$ & $3.487(1.721-7.067)$ & $p_{\mathrm{c}}=0.004$ \\
\hline IV vs. I & & & & $p_{\mathrm{c}}<0.001$ & $2.299(1.294-4.083)$ & $p_{\mathrm{c}}=0.020$ \\
\hline III vs. II & & & & $p_{\mathrm{c}}<0.001$ & $2.912(1.685-5.033)$ & $p_{\mathrm{c}}<0.001$ \\
\hline IV vs. II & & & & $p_{\mathrm{c}}=0.088$ & $1.823(1.056-3.149)$ & $p_{\mathrm{c}}=0.124$ \\
\hline IV vs. III & & & & $P=0.746$ & $1.182(0.428-3.267)$ & $P=0.747$ \\
\hline
\end{tabular}

Abbreviations: $\mathrm{HR}=$ hazard ratio; $95 \% \mathrm{CI}=95 \%$ confidence interval; Disease stage according to the TNM classification for colorectal cancer (UICC). ${ }^{*}$ If a significant difference was found, the Bonferroni correction was performed $\left(p_{\mathrm{c}}\right)$.

patients. Briefly, patient gender were stratified to male and female, age stratified to below and above the median age (65 years), categories $\mathrm{T}$ stratified to $\mathrm{T}_{1+2}$ and $\mathrm{T}_{3+4}, \mathrm{~N}$ stratified to $\mathrm{N}_{0}$ and $\mathrm{N}_{1+2}, \mathrm{M}$ stratified to $\mathrm{M}_{0}$ and $\mathrm{M}_{1}$, and clinical disease stage was stratified to I + II and III + IV, respectively.
Data showed that sHLA-G levels could significantly affects the CRC patient survival when clinical parameters were stratified. The detail results were shown in Table 4. The elder patients have poorer survival with sHLA$\mathrm{G}_{\text {high }}$ than those sHLA-G $\mathrm{G}_{\text {low }}(p=0.009$; Figure $3 \mathrm{Ab})$. Similarly, female patients with sHLA-G high have a 
significantly shoter survival than those with $\mathrm{sHLA}-\mathrm{G}_{\text {low }}$ ( $p=0.036$; Figure 3Bb). Moreover, patients with sHLA$\mathrm{G}_{\text {high }}$ exhibited a significant predictive power for CRC patients with $\mathrm{T}_{3+4}(p=0.038$; Figure $3 \mathrm{Cb}), \mathrm{N}_{0}(p=0.041$; Figure $3 \mathrm{Da})$, both $\mathrm{M}_{0}(p=0.014$; Figure $\left.3 \mathrm{Ea})\right)$ and $\mathrm{M}_{1}$ $(p=0.018$; Figure $3 \mathrm{~Eb})$, and clinical stage $(\mathrm{I}+\mathrm{II}, p=0.018$; Figure $3 \mathrm{Fa}$ ), respectively.

\section{DISCUSSION}

The aberrant HLA-G expression as a clinical biomarker for diagnosis or prognosis has been intensively investigated in tumors [8]. Both membrane-bound and sHLA-G proteins have similar immune suppression functions by directly binding to specific receptors such as immunoglobulin-like transcripts-2 and -4 expressed on immune cells $[20,21]$. HLA-G could also induce regulatory CD4+CD25+FoxP3+ T cells, B cells, DCs, NK cells and MDSCs, which provided these immune effectors with a long term immunomodulatory function [22-25].

Given to its immune suppressive property, peripheral sHLA-G could impair host antitumor immune response either locally at the tumor site or systemically
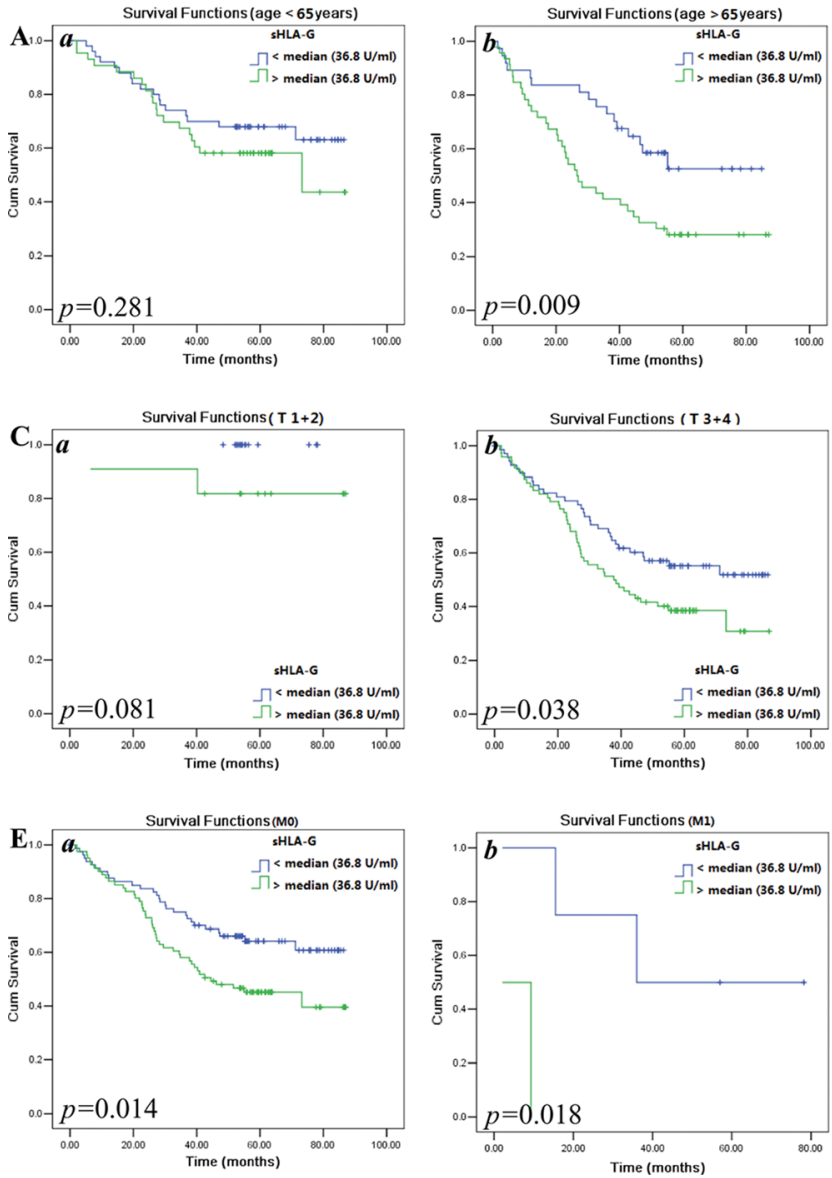
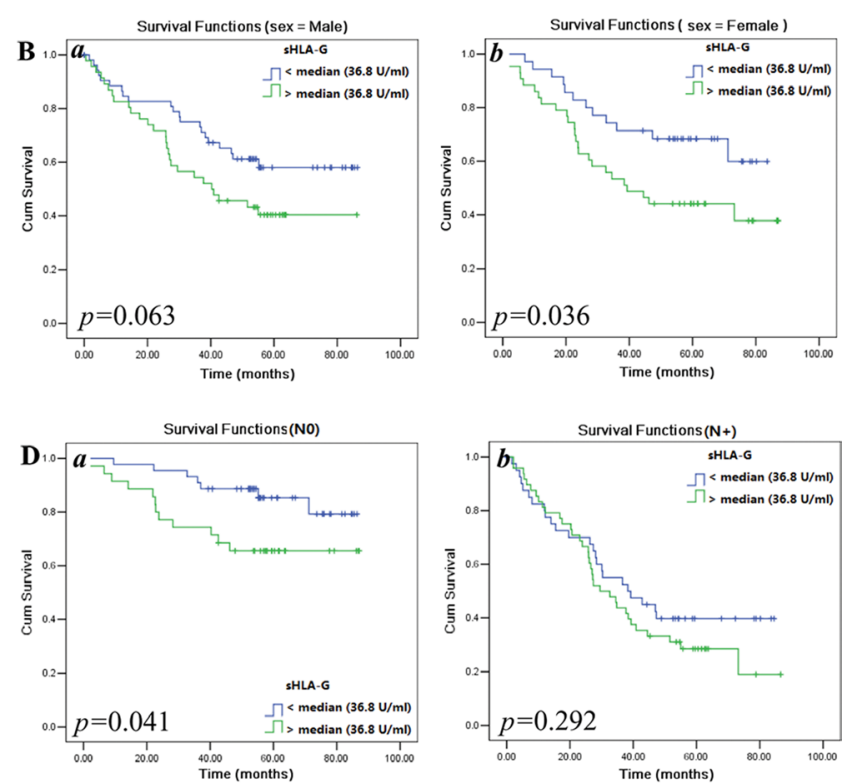

via the circulation. Previous studies revealed that plasma sHLA-G are significantly increased in patients with cancers such as lung cancer, breast and ovarian carcinoma as well as in patients with leukemia [26-28]. Beyond its suppressive immune functions, sHLA-G was considered as a diagnostic tool to distinguish between malignant and benign tumors or health controls, and as a prognostic factor in prediction of the disease outcome [16-18, 29].

In this scenario, sHLA-G was significantly increased in CRC patients, and SHLA-G is a powerful item to distinguish $\mathrm{CRC}$ from benign colorectal diseases, and the combination of sHLA-G and carcinoembryonic antigen showed a higher detection capacity than individual markers alone [15]. sHLA-G was also showed as a better diagnostic factor than carbohydrate antigen 125 in cervical and gastric cancer patients [16, 30]. In another study, sHLA-G was found exclusively elevated in NSCLC and sHLA-G could be a potent predictor for prognosis, that patients with sHLA-G less than $40 \mathrm{ng} / \mathrm{ml}$ have a significantly better survival [18]. In NSCLC patients, our study showed that increased sHLA-G was associated with the advanced disease stage and poor survival [19]. A recent study by Ben Amor et al. [17]. also showed
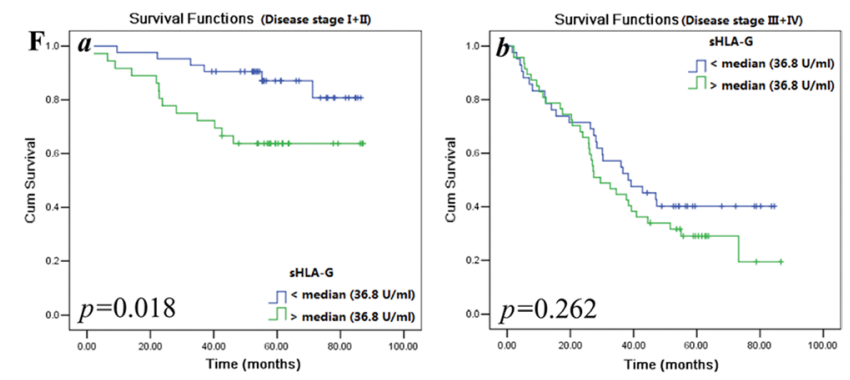

Figure 3: Kaplan-Meier survival analysis of stratified clinical parameters in survival by sHLA-G (sHLA-G sow $_{\text {low }}$ sHLA-G $\mathbf{G}_{\text {high }}$ ) in CRC patients, respectively. Stratified clinical parameters (A) patients with age below or above the median of 65 years; (B) male or female patients; (C) $\mathrm{T}_{1+2}$ or $\mathrm{T}_{3+4} ;\left(\right.$ D) $\mathrm{N}_{0}$ and $\mathrm{N}_{1+2} ;(\mathbf{E}) \mathrm{M}_{0}$ or $\mathrm{M}_{1}$; and (F) disease stage I + II or III + IV. 
Table 4: Log-rank Mantel-Cox analysis of stratified variables in survival by plasma sHLA-G levels in CRC patients

\begin{tabular}{|c|c|c|c|c|c|c|c|c|c|c|c|c|}
\hline \multirow[b]{2}{*}{ Variables } & \multirow{2}{*}{$\begin{array}{c}\text { Stratified } \\
\text { variables }\end{array}$} & \multicolumn{4}{|c|}{ Whole cohort } & \multicolumn{3}{|c|}{ sHLA-G $<36.8 \mathrm{U} / \mathrm{ml}$} & \multicolumn{3}{|c|}{ sHLA-G > $36.8 \mathrm{U} / \mathrm{ml}$} & \multirow[b]{2}{*}{$p$} \\
\hline & & $\begin{array}{l}\text { No. } \\
\text { Total }\end{array}$ & $\begin{array}{c}\text { No. } \\
\text { Events }\end{array}$ & $\begin{array}{c}\text { Survival time } \\
\text { Mean }(95 \% \mathrm{CI})\end{array}$ & $p$ & $\begin{array}{l}\text { No. } \\
\text { Total }\end{array}$ & $\begin{array}{c}\text { No. } \\
\text { Events }\end{array}$ & $\begin{array}{c}\text { Survival time } \\
\text { Mean }(95 \% \mathrm{CI})\end{array}$ & $\begin{array}{l}\text { No. } \\
\text { Total }\end{array}$ & $\begin{array}{c}\text { No. } \\
\text { Events }\end{array}$ & $\begin{array}{c}\text { Survival time } \\
\text { Mean }(95 \% \mathrm{CI})\end{array}$ & \\
\hline \multirow{2}{*}{ Gender } & Male & 100 & 48 & $55.3(48.7-61.9)$ & \multirow{2}{*}{0.777} & 54 & 21 & $61.0(52.2-69.8)$ & 46 & 27 & $48.9(39.3-58.4)$ & 0.063 \\
\hline & Female & 78 & 37 & $56.9(49.6-64.2)$ & & 35 & 12 & $63.8(54.4-73.1)$ & 43 & 25 & $49.7(39.7-59.7)$ & 0.036 \\
\hline \multirow{2}{*}{ Age } & $\leq 65$ ys & 95 & 36 & $62.4(56.0-68.8)$ & \multirow{2}{*}{0.005} & 52 & 17 & $65.1(56.6-73.6)$ & 43 & 19 & $58.4(48.7-68.1)$ & 0.281 \\
\hline & $>65 \mathrm{ys}$ & 83 & 49 & $48.8(41.6-56.1)$ & & 37 & 16 & $58.6(48.4-68.7)$ & 46 & 33 & $40.2(30.9-49.4)$ & 0.009 \\
\hline \multirow{2}{*}{$\begin{array}{l}\text { Tumor } \\
\text { status }\end{array}$} & $\mathrm{T}_{1+2}$ & 27 & 2 & $82.4(75.9-88.9)$ & \multirow{2}{*}{$<0.001$} & 16 & 0 & 1 & 11 & 2 & l & 0.081 \\
\hline & $\mathrm{T}_{3+4}$ & 142 & 76 & $52.7(47.3-58.2)$ & & 70 & 31 & $58.1(50.4-65.8)$ & 72 & 45 & $47.2(39.8-54.6)$ & 0.038 \\
\hline \multirow{2}{*}{$\begin{array}{l}\text { Nodal } \\
\text { status }\end{array}$} & $\mathrm{N}_{0}$ & 79 & 19 & $72.4(66.5-78.3)$ & \multirow{2}{*}{$<0.001$} & 44 & 7 & $77.8(71.8-83.8)$ & 35 & 12 & $65.2(54.8-75.6)$ & 0.041 \\
\hline & $\mathrm{N}_{1+2}$ & 90 & 59 & $44.0(37.4-50.7)$ & & 42 & 24 & $46.9(36.8-57.0)$ & 48 & 35 & $40.8(32.4-49.2)$ & 0.290 \\
\hline \multirow{2}{*}{$\begin{array}{l}\text { Metastasis } \\
\text { status }\end{array}$} & $\mathrm{M}_{0}$ & 163 & 74 & $58.2(53.2-63.2)$ & \multirow{2}{*}{0.160} & 82 & 29 & $63.7(56.9-70.6)$ & 81 & 45 & $52.3(45.2-59.3)$ & 0.014 \\
\hline & $\mathrm{M}_{1}$ & 6 & 4 & $36.6(11.6-61.5)$ & & 4 & 2 & $51.9(25.3-78.6)$ & 2 & 2 & $5.70(0.00-12.8)$ & 0.018 \\
\hline \multirow{2}{*}{$\begin{array}{l}\text { Disease } \\
\text { stage }\end{array}$} & $\mathrm{I}+\mathrm{II}$ & 78 & 19 & $72.2(66.2-78.2)$ & \multirow{2}{*}{$<0.001$} & 42 & 6 & $78.6(72.6-84.5)$ & 36 & 13 & $64.3(54.1-74.6)$ & 0.018 \\
\hline & III+IV & 91 & 59 & $44.5(37.9-51.1)$ & & 44 & 25 & $47.5(37.7-57.3)$ & 47 & 34 & $41.0(32.4-49.5)$ & 0.262 \\
\hline
\end{tabular}

Abbreviations: 95\% CI = 95\% confidence interval; TNM, lymph-node-metastasis and stage according to the TNM classification.

that NSCLC patients with sHLA-G above median level had a significantly shorter survival time and SHLA-G was an independent risk factor for NSCLC patients.

In this study, sHLA-G was significantly increased in CRC patients than that in normal controls, and much higher sHLA-G was observed in died than that in alive CRC patients. More importantly, CRC patients with sHLA- $\mathrm{G}_{\text {high }}$ had a statistically significant shorter survival time than those with sHLA- $G_{\text {low. }}$. In this context, other studies showed that with sHLA-G above $32 \mathrm{U} / \mathrm{ml}, 40 \mathrm{U} /$ $\mathrm{ml}$ and $50 \mathrm{U} / \mathrm{ml}$ were associated with a poor prognosis in NSCLC patients [17-19].

To be noted, clinical outcome significantly varies among patients within the same disease stage; however, the 'Immunoscore' components such as $\mathrm{CD} 3+, \mathrm{CD} 8+$ and $\mathrm{CD} 45 \mathrm{RO}+\mathrm{T}$ cell infiltration incorporating into traditional classification could improve classical TNM prognostic power [31]. Considering HLA-G is a powerful immune inhibitory antigen [8], whether sHLA-G could improve the performance of traditional predictors in CRC was evaluated in this study. Our study showed sHLA-G could significantly affects the CRC survival when traditional clinical parameters and prognosis predictors were stratified. In the group of sHLA- $\mathrm{G}_{\text {high }}$, we found that the female, the elder, and patients with $\mathrm{T}_{3+4}, \mathrm{~N}_{0}, \mathrm{M}_{0}$ and $\mathrm{M}_{1}$, and disease stage I+II, have dramatically poor survival than those with sHLA- $\mathrm{G}_{\text {low }}$.

Taken together, our study revealed that, besides sHLA-G could be an independent prognosis factor, the combination of sHLA-G with other traditional risk factors could improve their prognostic values for the particular subpopulations of CRC patients. Given its immune inhibitory property and prognostic value, sHLA-G in patients with CRC might be a new component for the 'Immunescore', contributing an additional significance to the classical cancer TNM classification system.

\section{MATERIALS AND METHODS}

\section{Patients and samples}

From April 2007 to May 2013, 178 plasma samples before surgery were consecutively collected from Chinese Han CRC patients (100 males and 78 females, aged from 28 years to 86 years), who were diagnosed and treated at Taizhou Hospital of Zhejiang Province, Wenzhou Medical University. Only patients with histopathologically confirmed of CRC were included in this study. None of the patients received radiotherapy, chemotherapy, or other medical interventions before blood sampling. Patient data including age, gender, date of initial diagnosis, TNM and disease stage were documented. The disease stage was determined according to the 7th TNM staging system by International Union for Cancer Control (UICC) and the American Joint Committee for Cancer (AJCC) [32].

Of 178 cases, the TNM status of 169 cases was available, where 24, 54, 85 and 6 patients with disease stage I, II, III and IV, respectively. Among these cases, 176 patients were available for the follow-up study till the last follow-up date at 25th, September 2014. Overall patient survival was defined as the time from the date of surgery to the date of last follow-up (censored) or patient death (event). The median follow-up for all patients was 47 months (range, 2-91), and during the entire period, there were 85 cancer-related deaths including 2, 17, 55 and 4 patients with stage I, II, III and IV, respectively.

Plasma samples from 113 sex- and age-matched (69 males and 44 females, aged from 22 years to 82 years), unrelated healthy Chinese Han individuals were served as normal controls. Plasma samples of patients and controls were prepared from the peripheral blood by centrifugation at $1500 \mathrm{~g}$ for 10 minutes, and stored at $-80^{\circ} \mathrm{C}$ until use. Written informed consent was obtained 
from each individual, and this study was performed following an Institutional Ethics Review Board approved protocol to investigate molecular markers relevant to $\mathrm{CRC}$ pathogenesis.

\section{sHLA-G enzymed-linked immunosorbent assay (ELISA)}

sHLA-G levels in plasma from 178 CRC patients and 113 unrelated healthy blood donors were determined. sHLA-G concentrations were determined with the sHLA-G specific ELISA kit (sHLA-G kit; Exbio, Prague, Czech Republic), which measures sHLA-G1 and HLA-G5. The optical densities were measured at $450 \mathrm{~nm}$ (Spectra Max 250, Molecular Devices, Sunnyvale, CA). The final concentration was determined by optical density according to the standard curves. The detection limits were $1 \mathrm{U} / \mathrm{ml}$. Details of the performance were according to the manufacture's instruction.

\section{Statistical analysis}

Statistical analysis was performed with SPSS 13.0 software (SPSS, Inc., Chicago, IL). Difference of sHLA-G between groups was analyzed with Mann-Whitney $U$-test. Overall patient survival was evaluated from the date of surgery to the event of interest or censored on the last follow-up. Survival probabilities were calculated using the Kaplan-Meier method. Differences between survival curves were analyzed by the log-rank test. Univariate and multivariate Cox regression analysis was used to define clinicopathological variables as independent predictors for overall survival. $p<0.05$ was considered significant.

\section{Authors' contributions}

Study design: AL WHY. Performed experiments: JBL YYR BH SSD. Material support and data acquisition: TNB. Performed statistical analysis and drafted the manuscript: AL WHY. All authors read and approved the final manuscript.

\section{ACKNOWLEDGMENTS}

This work was supported by grants from National Natural Science Foundation of China (31370920, 81372247), Zhejiang Provincial Natural Science Foundation of China (LR13H160001), Medical and Health Science and Technology Plan of Zhejiang Province (2014KYA225) and by Zhejiang Provincial program for the cultivation of high-level innovative health talents.

\section{CONFLICTS OF INTEREST}

The authors have declared no conflicts of interest.

\section{REFERENCES}

1. Chen W, Zheng R, Baade PD, Zhang S, Zeng H, Bray F, Jemal A, Yu XQ, He J. Cancer statistics in China, 2015. CA Cancer J Clin. 2016; 66:115-32.

2. Vinay DS, Ryan EP, Pawelec G, Talib WH, Stagg J, Elkord E, Lichtor T, Decker WK, Whelan RL, Kumara HM, Signori E, Honoki K, Georgakilas AG, et al. Immune evasion in cancer: Mechanistic basis and therapeutic strategies. Semin Cancer Biol. 2015; 35:S185-98.

3. Galon J, Pagès F, Marincola FM, Thurin M, Trinchieri G, Fox BA, Gajewski TF, Ascierto PA. The immune score as a new possible approach for the classification of cancer. J Transl Med. 2012; 10:1.

4. Nosho K, Baba Y, Tanaka N, Shima K, Hayashi M, Meyerhardt JA, Giovannucci E, Dranoff G, Fuchs CS, Ogino S. Tumour-infiltrating T-cell subsets, molecular changes in colorectal cancer and prognosis: cohort study and literature review. J Pathol. 2010; 222:350-66.

5. Ogino S, Nosho K, Irahara N, Meyerhardt JA, Baba Y, Shima K, Glickman JN, Ferrone CR, Mino-Kenudson M, Tanaka N, Dranoff G, Giovannucci EL, Fuchs CS. Lymphocytic reaction to colorectal cancer is associated with longer survival, independent of lymph node count, microsatellite instability, and $\mathrm{CpG}$ island methylator phenotype. Clin Cancer Res. 2009; 15:6412-20.

6. Yan WH. Human leukocyte antigen-G in cancer: are they clinically relevant? Cancer Lett. 2011;311:123-30.

7. Alegre E, Rizzo R, Bortolotti D, Fernandez-Landázuri S, Fainardi E, González A. Some basic aspects of HLA-G biology. J Immunol Res. 2014; 2014:657625.

8. Lin A, Yan WH. HLA-G expression in cancers: roles in immune evasion, metastasis and target for therapy. Mol Med; 2015; 21:782-91.

9. Carosella ED, Rouas-Freiss N, Tronik-Le Roux D, Moreau P, LeMaoult J. HLA-G: An Immune Checkpoint Molecule. Adv Immunol. 2015; 127:33-144.

10. Rebmann V, König L, Nardi Fda S, Wagner B, Manvailer LF, Horn PA. The Potential of HLA-G-Bearing Extracellular Vesicles as a Future Element in HLA-G Immune Biology. Front Immunol. 2016; 7:173.

11. Amodio G, Sales de Albuquerque R, Gregori S. New insights into HLA-G mediated tolerance. Tissue Antigens. 2014;84:255-63.

12. Xu YF, Lu Y, Cheng H, Jiang J, Xu J, Long J, Liu L, Ni Q, Liu C, Yu XJ. High Expression of Human Leukocyte Antigen-G is Associated with a Poor Prognosis in Patients with PDAC. Curr Mol Med. 2015;15:360-7.

13. Jeong S, Park S, Park BW, Park Y, Kwon OJ, Kim HS. Human leukocyte antigen-G (HLA-G) polymorphism and expression in breast cancer patients. PLoS One. 2014; 9:e98284.

14. Amiot L, Ferrone S, Grosse-Wilde H, Seliger B. Biology of HLA-G in cancer: a candidate molecule for therapeutic intervention? Cell Mol Life Sci. 2011; 68:417-31. 
15. Zhu CB, Wang CX, Zhang X, Zhang J, Li W. Serum sHLA-G levels: a useful indicator in distinguishing colorectal cancer from benign colorectal diseases. Int $\mathrm{J}$ Cancer. 2011; 128:617-22.

16. Pan YQ, Ruan YY, Peng JB, Han QY, Zhang X, Lin A, Yan WH. Diagnostic significance of soluble human leukocyte antigen-G for gastric cancer. Hum Immunol.2016; 77:317-24.

17. Ben Amor A, Beauchemin K, Faucher MC, Hamzaoui A, Hamzaoui K, Roger M. Human Leukocyte Antigen G Polymorphism and Expression Are Associated with an Increased Risk of Non-Small-Cell Lung Cancer and Advanced Disease Stage. PLoS One. 2016; 11:e0161210.

18. Schütt P, Schütt B, Switala M, Bauer S, Stamatis G, Opalka B, Eberhardt W, Schuler M, Horn PA, Rebmann V. Prognostic relevance of soluble human leukocyte antigen-G and total human leukocyte antigen class I molecules in lung cancer patients. Hum Immunol. 2010; 71:489-95.

19. Lin A, Zhu CC, Chen HX, Chen BF, Zhang X, Zhang JG, Wang Q, Zhou WJ, Hu W, Yang HH, Xu HH, Yan WH. Clinical relevance and functional implications for human leucocyte antigen-g expression in non-small-cell lung cancer. J Cell Mol Med. 2010; 14:2318-29.

20. Naji A, Durrbach A, Carosella ED, Rouas-Freiss N. Soluble HLA-G and HLA-G1 expressing antigen-presenting cells inhibit T-cell alloproliferation through ILT-2/ILT-4/FasLmediated pathways. Hum Immunol. 2007; 68:233-9.

21. Loumagne L, Baudhuin J, Favier B, Montespan F, Carosella ED, Rouas-Freiss N. In vivo evidence that secretion of HLA-G by immunogenic tumor cells allows their evasion from immunosurveillance. Int J Cancer. 2014; 135:2107-17.

22. Carosella ED, Gregori S, LeMaoult J. The tolerogenic interplay(s) among HLA-G, myeloid APCs, and regulatory cells. Blood. 2011; 118:6499-505.

23. Naji A, Menier C, Morandi F, Agaugué S, Maki G, Ferretti E, Bruel S, Pistoia V, Carosella ED, Rouas-Freiss N. Binding of HLA-G to ITIM-bearing Ig-like transcript 2 receptor suppresses B cell responses. J Immunol. 2014; 192:1536-46.
24. Agaugué S, Carosella ED, Rouas-Freiss N. Role of HLA-G in tumor escape through expansion of myeloid-derived suppressor cells and cytokinic balance in favor of Th2 versus Th1/Th17.Blood. 2011; 117:7021-31.

25. Baudhuin J, Migraine J, Faivre V, Loumagne L, Lukaszewicz AC, Payen D, Favier B. Exocytosis acts as a modulator of the ILT4-mediated inhibition of neutrophil functions. Proc Natl Acad Sci USA. 2013; 110:17957-62.

26. Provatopoulou X, Kalogera E, Sagkriotis A, Zagouri F, Nonni A, Zografos GC, Gounaris A. Soluble human leukocyte antigen-G expression in patients with ductal and lobular breast malignancy. Anticancer Res. 2012; 32:1021-6.

27. Mach P, Blecharz P, Basta P, Marianowski P, SkretMagierlo J, Kojs Z, Grabiec M, Wicherek L. Differences in the soluble HLA-G blood serum concentration levels in patients with ovarian cancer and ovarian and deep endometriosis. Am J Reprod Immunol. 2010; 63:387-95.

28. Własiuk P, Tomczak W, Zając M, Dmoszyńska A, Giannopoulos K. Total expression of HLA-G and TLR-9 in chronic lymphocytic leukemia patients. Hum Immunol. 2013; 74:1592-7.

29. Cao M, Yie SM, Liu J, Ye SR, Xia D, Gao E. Plasma soluble HLA-G is a potential biomarker for diagnosis of colorectal, gastric, esophageal and lung cancer. Tissue Antigens. 2011; 78:120-8.

30. Zheng N, Wang CX, Zhang X, Du LT, Zhang J, Kan SF, Zhu CB, Dong ZG, Wang LL, Wang S, Li W. Up-regulation of HLA-G expression in cervical premalignant and malignant lesions. Tissue Antigens. 2011; 77:218-24.

31. Fridman WH, Pagès F, Sautès-Fridman C, Galon J. The immune contexture in human tumours: impact on clinical outcome. Nat Rev Cancer. 2012; 12:298-306.

32. Edge SB, Compton CC. The American Joint Committee on Cancer: the 7th edition of the AJCC Cancer Staging Manual and the future of TNM. Ann Surg Oncol. 2010; 17:1471-4. 